\title{
ADSORPTION OF MULTIWALLED CARBON NANOTUBES ON ELECTROSPUN POLYCAPROLACTON NANOFIBERS
}

\author{
KHALID SAEED ${ }^{1,2,3 *}$, SOO-YOUNG PARK AND MOHAMMAD ISHAQ ${ }^{2}$ \\ ${ }^{1}$ Department of Chemistry, University of Malakand, Chakdara, Dir (Lower), \\ N.W.F.P. Pakistan \\ ${ }^{2}$ Institute of Chemical Sciences, University of Peshawar, Peshawar-25120, N.W.F.P. Pakistan \\ ${ }^{3}$ Department of Polymer Science, Kyungpook National University, \#1370 \\ Sankyuk-dong, Buk-gu, Daegu 702-701, South Korea \\ (Received: January 7, 2009 - Accepted: July 19, 2009)
}

\begin{abstract}
Polycaprolacton (PCL) and multiwalled carbon nanotubes/PCL (P-MWNT/PCL) were prepared by electrospinning technique. The average diameter of the nanofibers was below $400 \mathrm{~nm}$. The mechanical properties of the P-MWNT/PCL nanofibers were higher than that of neat PCL nanofibers. It was also found that the mechanical properties of the composite nanofibers were decreased as increased the amount of P-MWNTs, which were due to the poor dispersion of the P-MWNTs in the PCL matrix or agglomeration of MWNTs at high concentration. The thermal stability of the P-MWNT/PCL nanofibers was higher than PCL nanofibers. The conductivity of the adsorbed P-MWNT on PCL $(\varphi)$ nanofibers was $1.27 \times 10^{-4} \mathrm{~S} / \mathrm{cm}$.
\end{abstract}

Key Words: Polycaprolacton, Nanofibers, Adsorption, Carbon nanotubes.

\section{INTRODUCTION}

Carbon nanotubes (CNTs) were discovered by S. Iijima in 1991, have extraordinary electronic, thermal, and mechanical properties that make them useful materials for a variety of applications, such as heterogeneous catalyst supports, ${ }^{1-3}$ actuators, ${ }^{4}$ separation membranes,,${ }^{5,6}$ field emission devices, ${ }^{7}$ nano tube based composites, ${ }^{8}$ hydrogen storage, ${ }^{9}$ Chemical sensors,${ }^{10}$ and nanoelectronic devices. ${ }^{11}$ Prior to the discovery of nanotubes, no other material is known to possess such kind of unique combination of unique properties. They are proven to be the stiffest, strongest and the toughest fiber ever known. The earlier studies have shown that CNTs have extremely high Young's moduli, similar to that of the in-plane value for graphite $(\sim 1000 \mathrm{GPa}) .^{12}$ The specific tensile strength of a single layer of a MWNT is 100 times higher than that of steel, and the graphene sheet (in-plane) is stiffer than diamond at low strain. Furthermore, due to their molecular molecular perfection, they are essentially free of defects. ${ }^{13}$ Due to these unique properties, the incorporation of CNTs into a polymer matrix could improve the mechanical, thermal and electrical properties when compared to those of the original polymer matrix. Also the CNTs based composites show better properties than the composites which were reinforced by other reinforcing materials such as glass fibers, metal flakes, hollow microspheres, and carbon nano-fibers due to their high aspect ratio. ${ }^{14}$ Many polymers were used as host matrices for CNTs and the resulting composites have been found to show improved mechanical and electrical properties. ${ }^{15,16}$ The most commen techniques such as solution casting, ${ }^{17-19}$ melt processing,,$^{20,21}$ wet spinning, ${ }^{22-24}$ and electrospinning are used to fabricate CNT-composite materials. ${ }^{25}$

Electrospinning is an interesting process for producing non-woven fibers and consider to be a simple and effective technique for the making of polymer fibers, inorganic fibers and composite fibers with an average diameters ranging from micro to nanoscales. ${ }^{26,27}$ In this process, a fiber is drawn from a polymer solution or a melt by applying high electrostatic forces to deposit on a metallic collective screen. The appearance of the collected fibers depend on many factors such as viscoelastic force (depend on solution concentration, average molecular weight of the polymer, and viscosity of the solution), surface tension, gravitational force (dependent on solution density), and electrostatic force and the conductivity of the solution. ${ }^{28-31}$ The nanofibers have interesting characteristics such as large surface area per unit mass, high porosity, high gas permeability, high fiber aspect ratio, and small interfibrous pore size. Due to these unique characteristic, the nanofibers shows a wide range of applications such as sensor, ${ }^{32}$ scaffolds in tissue engineering, ${ }^{33}$ drug delivery, ${ }^{34}$ wound dressing,${ }^{35}$ nanofibers as a filter, ${ }^{36}$ protecting clothing ${ }^{37}$ nanofiller materials. ${ }^{38}$

In the present study, we prepared the PCL and MWNTs/PCL composite nanofibers, in order to study the effect of MWNTs on the thermal stability, mechanical and electrical properties of PCL nanofibers. The incorporation of CNTs improve significantly the mechanical properties of the nanofibrous membranes,${ }^{39}$ but their electrical properties are lower than those of composite films with the same concentration of CNTs. It might be due to the high porosity of the membranes and the excellent wrapping of the polymers around the CNTs. ${ }^{12}$ In our study we also dispersed MWNTs in water (contains a surfactant) by sonication and adsorbed them on the PCL electrospun nanofibers. The adsorbed MWNT nanofibers membranes not only shown the electrical properties, but also retain the inherent characteristics (like their high porosity and flexibility) of the nanofibrous membranes.

\section{EXPERIMENTAL}

\section{Material}

Chloroform and methanol (64-66 \% purity), and Sodium dodecyl sulfate (SDS) were purchased from Ducksan and DC Chemical, Republic of Korea, respectively. PCL (average molecular weight 90,000) and the composites were prepared by the same way as reported in our published article [40]. The MWNTs ( $97 \%$ purity) were supplied by Iljin Nanotec ${ }^{\odot}$ and were manufactured by thermal chemical vapor deposition. ${ }^{41}$

\section{Electrospinning}

The solutions of the PCL and MWNT/PCL nanocomposites were prepared by dissolving a $15 \mathrm{wt} \%$ sample in a mixture of chloroform and methanol (3:1 ratio). ${ }^{25}$ The MWNT/PCL nanocomposite solutions were sonicated for $1 \mathrm{~h}$ in order to obtain a homogeneous dispersion. The prepared PCL solution was added to a $10-\mathrm{mL}$ glass syringe with a needle tip diameter of $0.5 \mathrm{~mm}$. The feeding rate of the polymer solution was $2 \mathrm{~mL} / \mathrm{h}$, which was controlled by a syringe pump. The electrospinning voltage $(15 \mathrm{kV})$ was applied to the needle at room temperature and the distance between the needle tip and collector was $11 \mathrm{~cm}$. At a critical voltage, the jet of the polymer solution came out from the needle tip and was collected on the collector. When the solvent evaporated, a non-woven PCL mate was formed. The same experimental conditions were applied for the MWNT/PCL nanocomposites.

\section{Adsorption of MWNTs on PCL Nanofibrous Membranes}

The pristine MWNTs were dispersed in distilled water $(0.2 \mathrm{mg} / \mathrm{mL})$ and sodium dodecyl sulfate (SDS, anionic) was employed as the surfactants $(0.3 \mathrm{wt}$ $\%$ in water). The slurry was then sonicated for $5 \mathrm{~h}$ at room temperature.

The electrospun membranes of PCL were immersed for $5 \mathrm{~min}$ in a glass bath contained the dispersed MWNTs, rinsed three times in deionized water, and dried under ambient conditions.

\section{Instrumentation}

The micrographs of the gold-coated electrospun PCL and MWNT/PCL composite nanofibers were analyzed using a JEOL JSM-5910 scanning electron microscope (SEM). 
The conductivity of the film samples was measured at $25{ }^{\circ} \mathrm{C}$ with a four-point probe method using a HMS- $3000\left(\mathrm{Ecopia}^{\circ}\right)$. The dimensions of the samples were $\sim 15$ (length) $\times 15$ (width) $\times 0.4$ (thickness) $\mathrm{mm}^{3}$ and their ends were coated with an indium paste to ensure good electrical contact. The measurable conductivity range in this instrument was between $10^{3}$ and $10^{-6} \mathrm{~S} /$ $\mathrm{cm}$.

The tensile properties were measured using an Instron (Model M 4465). The tests were carried out at room temperature with $30 \mathrm{~mm}$ gauge length and a $10 \mathrm{~mm} / \mathrm{min}$ crosshead speed. The specific tensile strength and modulus were calculated because the pores in the cross-section of the nanofiber mat do not give true stress if the cross-section area is used for calculating the nominal stress. They were calculated by dividing the force by weight per length.

The TGA thermograms of the PCL and the P-MWNT/PCL composite nanofibers were obtained in a nitrogen atmosphere, at a heating rate of $20^{\circ} \mathrm{C} /$ min between 25 and $1000{ }^{\circ} \mathrm{C}$ using a Diamond TG/DTA (Perkin Elmer).

\section{RESULTS AND DISCUSSION}

Figure 1 shows the SEM images of the electrospun PCL nanofibers. The nanofiber could not be formed when the PCL concentration in the solution was lower than $7 \mathrm{wt} \%$, it was only sprayed on a collector. However, the formation of fibers with beads was observed by increasing the concentration of PCL $(7,10$, and $15 \mathrm{wt} \%)$. The number of beads were decreased as increased the concentration of the PCL. The diameters of the electrospun PCL was $400 \pm 50$ $\mathrm{nm}$. After optimization of electrospinning process for PCL solutions in solvent mixture (chloroform and methanol), P-MWNT/PCL nanocomposite solutions were electrospun to nanofibers. The diameters of the electrospun P-MWNT/ PCL composite nanofibers were also below $400 \mathrm{~nm}$ (Figure 1b).

Figure 1c show the SEM images the PCL nanofibrous membrane obtained after dipping them in an aqueous MWNTs solution. The MWNTs are present in the form of aggregating/bundles due to van der Waals interaction between them. In order to disperse them in aqueous media, the SDS surfactants were used, which results a homogenous black ink like solutions after sonication. ${ }^{12} \mathrm{It}$ was observed that the color of the non-woven membranes changes from white to grey due to the presence of MWNTs. The MWNTs were adsorbed not only on the surface of the nanofibers, but also maintained the high porosity of the membranes. After washing with distilled water the $\varphi$ nanofibers membranes, the MWNTs still remained on the surface of the nanofibers (Figure1c). It presented that the MWNTs are not simply deposited on the surface of nanofiber, but there is a strong interaction between the MWNTs and the PCL, which make them to adhere to each other.

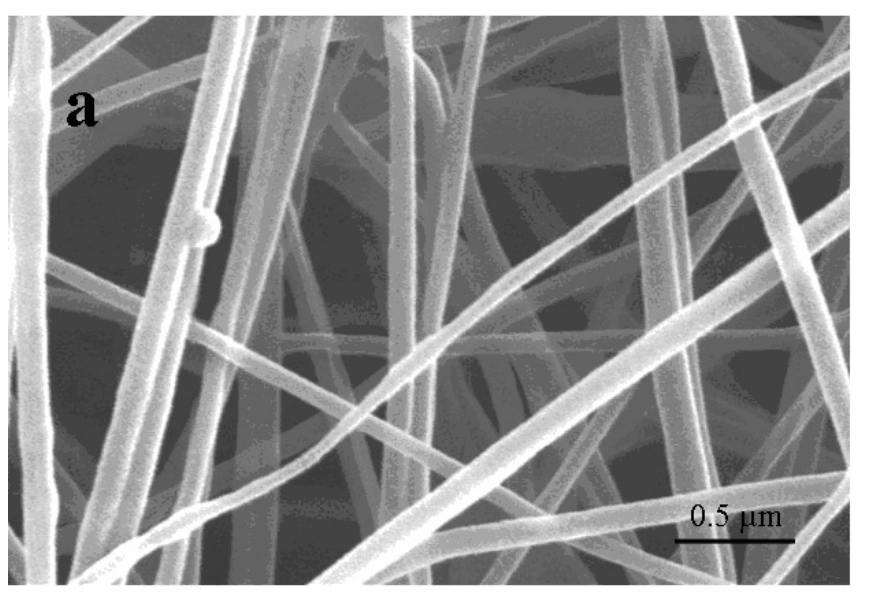



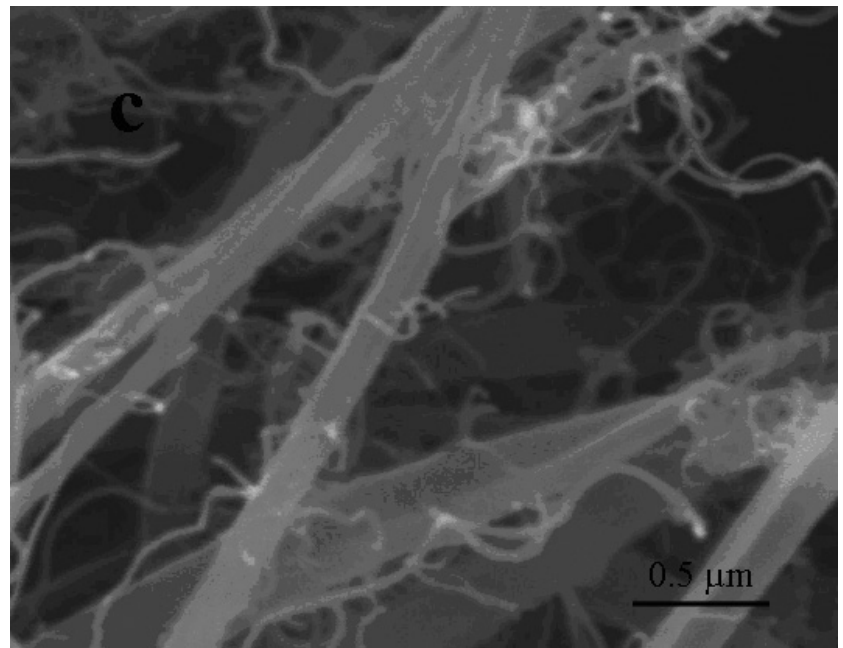

Figure 1(a): SEM images of electrospun PCL, (b) $2 \mathrm{wt} \%$ P-MWNT/PCL and (c) $\varphi$ nanofibers.

\section{Mechanical properties of MWNT/PCL nanofibers}

Table 1 shows the tensile properties of the nanofibers. The specific tensile strengths of the 1 and $2 \mathrm{wt} \%$ P-MWNT/PCL, and the PCL nanofibers were 62,50 and $25 \mathrm{kgfcm} / \mathrm{g}$, respectively, and the specific modulus of them were 101,103 , and $97 \mathrm{kgfcm} / \mathrm{g}$, respectively. The specific tensile strength and modulus of MWNT/PCL nanofibers were enhanced as compared to those of the PCL, which indicated that the composite nanofibers were tougher and more resistance to deformation. ${ }^{42}$ The elongation at break of P-MWNT/PCL was also higher than that of pure PCL nanofibers. It was also observed that the mechanical properties of the composite nanofibers were decreased as increased the amount of MWNT, which are due to the poor dispersion of the P-MWNTs in the PCL matrix or agglomeration of MWNTs at high concentration. ${ }^{43}$ The bead formation might be another possibility for the low mechanical properties of the P-MWNT/PCL nanofibers. The low mechanical properties for beaded nanofibers were also reported by Inai et al. ${ }^{44}$

Table 1. Mechanical properties of PCL and P-MWNT/PCL nanofibers.

\begin{tabular}{|c|c|c|c|}
\hline Samples & $\begin{array}{c}\text { Specific Tensile } \\
\text { Strength } \\
\text { (kgf cm/g) }\end{array}$ & $\begin{array}{c}\text { Specific } \\
\text { Modulus } \\
\text { (kgf cm/g) }\end{array}$ & $\begin{array}{c}\text { Elongation } \\
\text { at break } \\
(\%)\end{array}$ \\
\hline PCL & $25.8 \pm 03.6$ & $97.5 \pm 15.6$ & $20.7 \pm 03.4$ \\
\hline $\begin{array}{c}\text { P-MWNT/PCL } \\
1 \text { wt \% MWNTs } \\
2 \text { wt \% MWNTs }\end{array}$ & $62.7 \pm 15.9$ & $101.1 \pm 28.7$ & $53.0 \pm 0.1$ \\
\hline
\end{tabular}




\section{Conductivity Measurements}

The conductivities of $2 \mathrm{wt} \%$ P-MWNT/PCL film, $\varphi$ and $2 \mathrm{wt} \% \mathrm{P}-\mathrm{MWNT} /$ PCL nanofibers were shown in table 2, which was measured by using fourpoint probe method. The film was prepared by compression molding of the P-MWNT/PCL nanocomposites. The $2 \mathrm{wt} \%$ P-MWNT/PCL nanocomposite films and $\varphi$ nanofibers showed electrical conductivity $1.68 \times 10^{-2}$ and $1.269 \times$ $10^{-4} \mathrm{~S} / \mathrm{cm}$, respectively. While conductivity for electrospun $2 \mathrm{wt} \% \mathrm{P}-\mathrm{MWNT} /$ PCL and neat PCL nanofibers was not detected within the instrument detection limit (below $10^{-6} \mathrm{~S} / \mathrm{cm}$ ). The lower electrical conductivity of $2 \mathrm{wt} \% \mathrm{P}-\mathrm{MWNT} /$ PCL nanofibers than those of $2 \mathrm{wt} \%$ P-MWNT/PCL composite films with the same concentration of CNTs, were due to the high porosity of the membranes and the excellent wrapping of the polymers around the CNTs. ${ }^{12}$ film.

Table 2: Conductivity of $\varphi$ and P-MWNTs/PCL, $\phi$ and nanofibers and

\begin{tabular}{|c|c|}
\hline Samples & Conductivity $(\mathrm{S} / \mathrm{cm})$ \\
\hline $\begin{array}{c}2 \mathrm{wt} \% \text { P-MWNT/PCL } \\
\text { Nanofibers }\end{array}$ & ----- \\
\hline$\phi$ nanofibers & $1.27 \times 10^{-4}$ \\
\hline $2 \mathrm{wt} \%$ P-MWNT/PCL film & $1.68 \times 10^{-2}$ \\
\hline
\end{tabular}

------- below the instrument limit

Figure 2 shows TGA curves of the PCL, P-MWNT ( $2 \mathrm{wt} \%) / \mathrm{PCL}$, and $\varphi$ Nanofibers. The pure PCL nanofibers started to lose weight at $310{ }^{\circ} \mathrm{C}$ and completely decomposed at about $460^{\circ} \mathrm{C}$. The thermograms of the P-MWNT (2 $\mathrm{wt} \%$ )/PCL and $\varphi$ nanofibers showed that the weight lose started at about 340 ${ }^{\circ} \mathrm{C}$, which is about $30^{\circ} \mathrm{C}$ higher than the pure PCL. It indicated that a significant shift of the weight loss occur towards higher temperature. The increase of the degradation temperature indicated that the P-MWNTs increased the thermal stability of the polymer nanofibers.

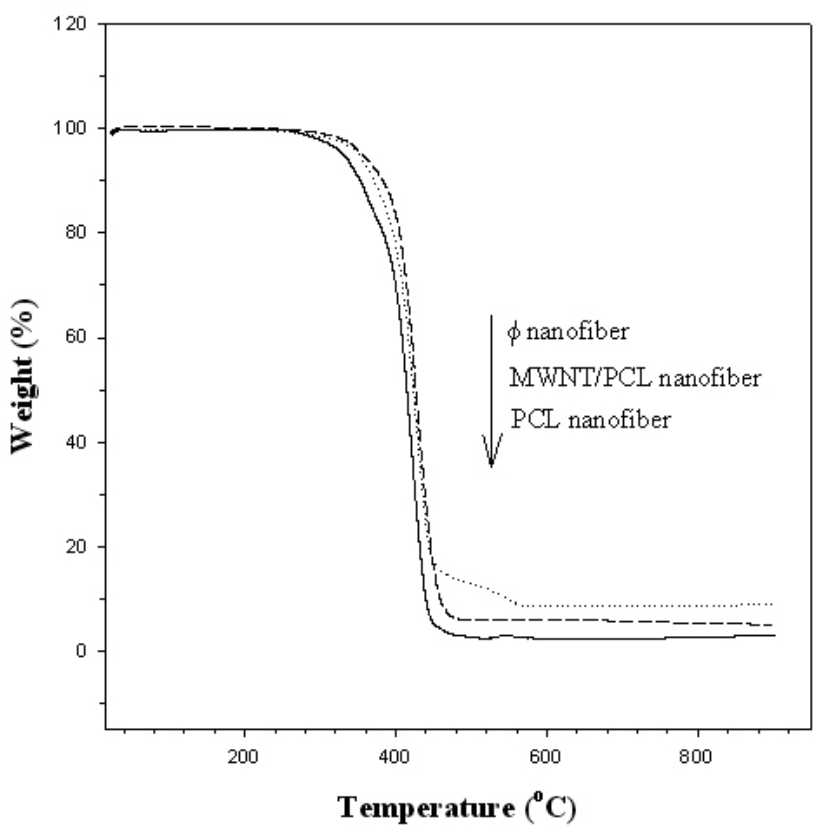

Figure 2: TGA thermograms of electrospun PCL, 2 wt \% P-MWNT/PCL and $\varphi$ nanofibers.

\section{CONCLUSION}

The adsorption of MWNTs onto the surface of PCL nanofiber is simple method to obtain electrically conductive non-woven membranes. The MWNTs were dispersed by SDS in aqueous media and adhere to the surface of the PCL nanofibers. The conductivity of the adsorbed $\varphi$ nanofibers was $1.27 \times 10^{-4} \mathrm{~S} / \mathrm{cm}$ while the conductivity was not detected for $2 \mathrm{wt} \%$ P-MWNT/PCL nanofibers within the instrument detection limit (below $10^{-6} \mathrm{~S} / \mathrm{cm}$ ). The mechanical properties (specific strength specific modulus and elongation at break) of the nanocomposite nanofibers were higher than that of neat PCL nanofibers, which decreased as increased the amount of P-MWNTs.

\section{REFERENCES}

1. G. Che, B. B. Lakshmi, E. R. Fisher, C. R. Martin, Nature, 393, 346, (1998).

2. G. Che, B. B. Lakshmi, C. R. Martin, E. R. Fisher, Langmuir, 15, 750 (1999)

3. W. Li, C. Liang, J. Qiu, W. Zhou, H. Han, Z. Wei, G. Sun, Q. Xin, Carbon, 40, 791, (2002)

4. R. H. Baughman, C. Cui, A. A. Zakhidov, Z. Iqbal, J. N. Barisci, G. M. Spinks, G. G. Wallace, A. Mazzoldi, D. D. Rossi, A. G. Rinzler, O. Jaschinski, S. Roth, M. Kertesz, Science, 284, 1340, (1999).

5. L. Sun, R. M. Crooks, J. Am. Chem. Soc., 122, 12340, (2000).

6. L. Zhang, A. V. Melechko, V. I. Merkulov, M. A. Guillorn, M. L. Simpson, D. H. Lowndes, , M. J. Doktycz, Appl. Phys. Lett., 81, 135, (2002).

7. De Heer, W A, Chatelain, A, Ugarte, D, Science, 1995, 270: 1179.

8. K. Saeed, S. -Y. Park, J. Appl. Polym. Sci., 106, 3729, (2007).

9. C. Liu, Y. Y. Fan, M. Liu, H. T. Cong, H. M. Cheng, M. S. Dresselhaus, Science, 286, 1127, (1999).

10. J. Kong, N. R. Franklin, C. Zhou, M. G. Chapline, S. Peng, K. Cho, H. Dai, Science 287, 622, (2002).

11. S. J. Tans, A. R. M. Verschueren, C. Dekker, Nature, 393, 49, (1998).

12. H. S. Kim, H.-J. Jin, S. J. Myung, M. Kang, I.-J. Chin, Macromol. Rapid Commun., 27, 146, (2006).

13. K. Laxminarayana, N. Jalili, Textile Res. J., 75, 670, (2005),

14. S. Cui, R. Canet, A. Derre, M. Couzi, P. Delhaes, Carbon, 41, 797, (2003).

15. A. T. Seyhan, F. H. Gojny, M. T. K. Schulte, Europ. Polym. J., 43, 374, (2007).

16. Q. Wang, J. Dai, W. Li, Z. Wei, J. Jiang, Compos. Sci. Thecnol., 68, 1644, (2008).

17. M. S. P. Shaffer, A. H. Windle, Adv. Mater., 11, 937, (1999).

18. D. Qian, E. C. Dickey, R. Andrews, T. Rantell, Appl. Phys. Lett., 76, 2868, (2000).

19. B. Safadi, R. Andrews, E. A. Grulke, J. Appl. Polym. Sci., 84, 2660, (2002).

20. W. D. Zhang, L. Shen, I. Y. Phang, T. Liu, Macromolecules, 37, 256 , (2004).

21. P. Potschke, T. D. Fornes, D. R. Paul, Polymer, 43, 3247, (2002).

22. B. Vigolo, A. Penicaud, C. Coulon, C. Sauder, R. Pailler, C. Journet, P. Bernier, P. Poulin, Science, 290, 1331, (2000).

23. B. Vigolo, P. Poulin, M. Lucas, P. Launois, P. Bernier, Appl. Phys. Lett., 81, 1210, (2002)

24. S. Kumar, T. D. Dang, F. E. Arnold, A. R. Bhattacharyya, B. G. Min, X. Zhang, R. A.Vaia, C. Park,W.W. Adams, R. H.Hauge, R. E. Smalley, S. Ramesh, P. A. Willis, Macromolecules, 35, 9039, (2002).

25. K. Saeed, S. -Y. Park, H. -J. Lee, J. -B. Baek, W. -S. Huh, Polymer, 47, 8019, (2006).

26. Y.M Shin, M.M. Hohman, M.P. Brenner, G.C. Rutledge, Polymer, 42 , 9955, (2001).

27. Z. M. Huang, Y.Z. Zhang, M. Kotaki, S. Ramakrishna, Compos. Sci. Thecnol., 63, 2223, (2003).

28. I. D. Norris, M. M Shaker, F. K. Ko, A G. MacDiarmid, Synth. Metals, 114,109, (2000).

29. M. M Demir, I. Yilgor, E. Yilgor, B. Erman. Polymer, 43, 3303, (2002)

30. H. Fong, I. Chun, D. H.Reneker, Polymer, 40, 4585, (1999).

31. T. Jarusuwannapoom, W. Hongrojjanawiwat, S. Jitjaicham, , L. Wannatong, M. Nithitanakul, C. Pattamaprom, P. Koombhongse, R. Rangkupan, P. Supaphol, Europ. Polym. J., 41, 409, (2005).

32. D. Aussawasathien, J. -H. Dong, L. Dai, Synth. Met., 154, 37, (2005).

33. C. J. Buchko, L. C. Chen, Y. Shen, D. C. Martin, Polymer, 40, 7397, (1999). 
34. E. -R. Kenawy, G. L. Bowlin, K. Mansfield, J. Layman, D. G. Simpson, E. H. Sanders, et al., J. Controlled Release, 81, 57, (2002).

35. M. S. Khil, D. I. Cha, H. Y. Kim, I. S. Kim, N. Bhattarai, J. Biomed. Mater. Res. B: Appl. Biomater., 67, 675, (2003).

36. K. Saeed, S. Haider, T. -J. Oh, S. -Y. Park, J. Membrane Sci., 322, 400 , (2008).

37. P. Gibson, H. Schreuder-Gibson, D. Rivin, Colloids Surf. A: Phys-Chem. Eng. Asp., 187-188, 469, (2001).

38. M. M. Bergshoef, G .J. Vancso, Adv. Mater., 11, 1362, (1999).

39. S. D. McCullen, K. L. Stano, D. R. Stevens, W. A. Roberts, N. A. Monteiro-Riviere, L. I. Clarke, R. E. Gorga, J. Appl. Polym. Sci., 105, $1668,(2007)$
40. K. Saeed, S. -Y. Park, J. Appl. Polym. Sci., 104, 1957, (2007).

41. http://www.iljinnanotech.co.kr.

42. J. Goa, M. E. Itkis, A.Yu, E. Bekyarova, B. Zhao, R. C. Haddon, J. Am. Chem. Soc., 127, 3847, (2005).

43. J. Ayutsede, M. Ganghi, S. Sukigara, H. Ye, C. -M. Hsu, Y. Gogotsi, F. Ko, Biomacromolecules, 7, 208, (2006).

44. R. Inai, M. Kotaki, S. Ramakrishna, J. Appl. Polym. Sci: Part B: Polym. Phys., 43 3205, (2005). 